\title{
The Concept of a Compact Profile Agricultural Tractor Suitable for Use on Specialised Tree Crops
}

\author{
Simone Pascuzzi * ${ }^{\circ}$, Alexandros Sotirios Anifantis $(\mathbb{D}$ and Francesco Santoro \\ Department of Agricultural and Environmental Science, University of Bari Aldo Moro, Via Amendola 165/A, \\ 70126 Bari, Italy; alexandrossotirios.anifantis@uniba.it (A.S.A.); francesco.santoro@uniba.it (F.S.) \\ * Correspondence: simone.pascuzzi@uniba.it
}

Received: 4 March 2020; Accepted: 11 April 2020; Published: 11 April 2020

\begin{abstract}
This study firstly examined certain methods of vineyard management typically adopted in Apulia for both table grapes and wine grapes. In the later phenological stages, guyot or spurred cordon vineyards have extremely abundant vegetation, which drastically limits the space available between the rows for the passage of a tractor, even for a narrow-track vehicle. On the other hand, vegetation in tendone vineyards is situated at approximately $1.90 \mathrm{~m}$ above the soil surface, so that total tractor height must be compatible with this cultivation method. Foliage canopies in these types of vineyard cultivation system were evaluated at the times of their maximum growth in order to identify the maximum possible size of a prototype tractor that would be able to pass between vineyard rows without interfering in any way with the vegetation and fruits. Using the results of field measurements, it was established that the prototype tractor must have a maximum height of $1600 \mathrm{~mm}$, with a minimum front axle track of less than $1100 \mathrm{~mm}$ and a back axle track of less than $1000 \mathrm{~mm}$. A tractor built to these specifications is now being tested in order to compare its performance with that of other tractors commonly used in Apulia in various agricultural contexts.
\end{abstract}

Keywords: compact tractor; rops; safety; tendone vineyards; guyot vineyards

\section{Introduction}

In agriculture, the commonest type of fatal accident is due to tractor rollover [1-3]. The most common causes of this are as follows: (i) rough and unstable terrain; (ii) the high torque on the drive wheels; (iii) towing heavy or unbalanced loads; (iv) steep gradients [4-6]. In recent decades, different technical solutions have been adopted in order to reduce the impacts on the tractor driver of this kind of event [7-9]. These include the passive solution of fitting the tractor with an ROPS (roll over protective structure) and a seatbelt fixed to the driving seat that will anchor and protect the driver from being crushed by the tractor if it rolls over [10-12]. There are different kinds of ROPS, ranging from a tiltable 2-pillar front roll-bar, to a ROPS that encloses a soundproofed cabin with air-conditioning [13,14]. In particular, 2-pillar front roll-bars were introduced around the mid-1980s on narrow axle track tractors (used especially with specialised crops, for the maintenance of green areas and for greenhouses) to enable tractors to pass under vegetation canopies without damaging lower branches and shoots [13-15].

A roll-bar is designed to stay in the vertical upright position (protection) during all stages of tractor use, but must be lowered during passage under canopy between crop rows in order to avoid interfering with foliage and fruits [16-19]. In addition, many specialised tractors have a relatively high centre of gravity and a reduced ground clearance that often makes it impossible to perform normal cultivation tasks in particular specialised crops [20-23]. In this respect, it needs to be said that the specialized tractor sector has a plenty of different solutions and many manufacturers (Landini, Fendt, Massey Ferguson, and so on) offer a range of highly innovative models, which are characterized by 
compactness, ergonomics, comfort, and design. They have an average power ranging from 50 to $80 \mathrm{~kW}$ and are designed to respond in the most effective way to the specific needs of farms. All these models are fitted with either simple front and rear roll-bars on the driver's seat or a closed suspended soundproof and air-conditioning cab. The tiltable 2-pillar front roll-bar arranged in a horizontal position is not effective for the driver's safety, but significantly reduces the overall height of the tractor (also less than $1400 \mathrm{~mm}$ ), making transits possible under orchard vegetation canopies without difficulties. Conversely, the tiltable 2-pillar front roll-bar arranged in a vertical position, is surely effective for the operator's safety but the overall height of the tractor exceeds $2000 \mathrm{~mm}$ and in these conditions, transit under canopy is very difficult if not impossible. To carry out operations under crop canopies, which require the use of the tractor, usually the workers lower the roll-bar, negating the effectiveness of the safety device. Taking this in mind, INAIL (the Italian National Insurance Institute for Occupational Labour) has funded a project, named TRACLAS, involving several Operational Units of Italian universities, with the aim of developing a compact tractor suitable for use on specialised tree crops, equipped with a fixed ROPS that always works regardless of what agricultural operation is carried out. The initial stage of this project consisted of an in-depth study of the principal specialised crops grown in Italy: grapevines, olives, apples, hazelnuts, etc. This included analysis of the relative cultivation systems, the salient features of the tractors and implements currently used (theoretical and real working capacity, required capacity, operating speed, etc.) and of the tractors that tow these implements (power; measurements, etc.) [24-26]. Therefore, each operational unit analysed the crops grown in its own reference area. The Department of Agricultural and Environmental Science of the Aldo Moro University of Bari (Bari, Italy), a partner in this project, examined different types of cultivation used in Apulian vineyards for wine grapes and for table grapes. The particular climatic conditions of Apulia mean that the vegetation of guyot or spurred cordon vines is especially abundant in the later phenological stages. This drastically reduces the space available for tractors to drive between the rows, even when a narrow-track vehicle is used $[27,28]$.

On the other hand, the vegetation in a tendone vineyard, whether it produces wine grapes or table grapes, grows on a horizontal plane at approximately $1.90 \mathrm{~m}$ above the soil surface, which means that total tractor height is a significant parameter in relation to the cultivation tasks performed in this type of vineyard, in terms of effectiveness and of driver safety $[29,30]$. For these types of vineyard, canopy volumes were analysed during their period of greatest expansion to ascertain the maximum possible size of a tractor able to drive between the rows of the vineyard without interfering in any way with the vegetation and fruiting areas [31,32]. The results of this study concerning the Apulian vineyards, which are reported in this paper, were then merged with those concerning the surveyed specialized crops by the other operating units participating in the TRACLAS project. The elaboration of all the data allowed us to define the overall size and performance characteristics of the compact agricultural tractor as required by the aim of the funded project.

\section{Materials and Methods}

Experimental evaluation of the total extent occupied by the vine canopies was carried out in order to ascertain the space available for agricultural vehicles to pass between rows when canopies are at their maximum expansion [33-35]. The two vineyards selected have locations and cultivation methods that represent most production of wine grapes and table grapes, respectively, in Apulia. Vegetation canopies were measured in July 2018, i.e., at the time of their greatest expansion, which is thus the most critical time of the year for the passage of agricultural vehicles between the rows of vines.

\subsection{The Vineyards Examined}

The selected vineyards were: (i) Cantine Due Palme near Cellino San Marco (Apulia, Brindisi Province, Italy), which produces wine grapes using the guyot system; (ii) Porrelli near Rutigliano (Bari Province), which produces table grapes using the tendone system. The salient characteristics of the Cantine Due Palme vineyard were as follows: area under cultivation, 57.0 ha; vine spacing (guyot), 
$2.2 \times 1.0 \mathrm{~m}$; inter-row width, $2.2 \mathrm{~m}$. Observations involved the following cultivars: Negroamaro, Aglianico (yellow leaf), Malvasia nera, Lambrusco, Primitivo and Falanghina.

The salient characteristics of the Porrelli vineyard were as follows: tendone vineyard area, 2.7 ha; vine spacing (pergola), $2.2 \times 2.2 \mathrm{~m}$; inter-row width, $2.20 \mathrm{~m}$. Observations involved the cultivar Timpson (white grapes).

\subsection{Evaluation of the Overall Dimension of the Canopy}

For each cultivar examined, representative statistical sampling of the average canopy dimensions was performed according to the following protocol [7]. For each vineyard, we randomly chose 10 pairs of plants located alternatively on two adjacent rows that were in a central position in the vineyard itself, in such a way as to be representative of a wide area of the entire plot (Figure 1).

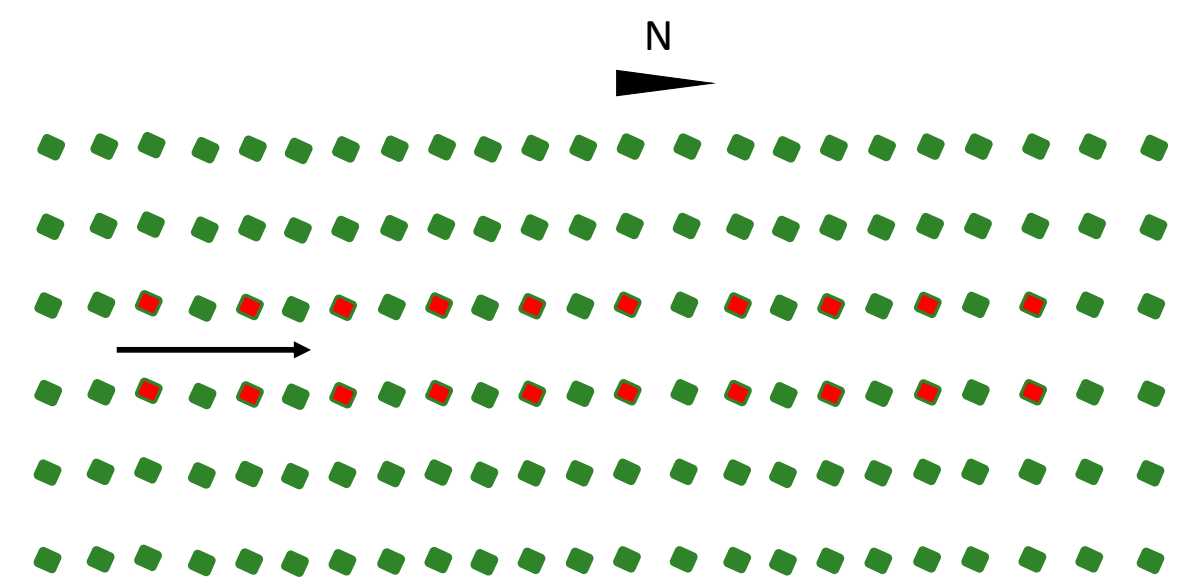

Figure 1. Position of the pairs of plants inside the examined vineyards.

Each pair of plants was photographed using a Nikon D3100 digital camera, set on a tripod at an equal distance from the two adjacent rows, and with the centre of the objective at a height of $1.30 \mathrm{~m}$ above the ground surface (Figure 2a,b). Considering that, as an average, the height above the ground level of the top of the canopy of both guyot and tendone systems was $1.90 \mathrm{~m}$ and that the canopy itself started at $0.70 \mathrm{~m}$ above the ground level, the centre of the objective was placed at the mean value between the aforesaid elevations. The different pictures in the vineyard were taken at around noon in order to avoid the possible disturbing effects of the shadows and, in order to avoid possible canopy contour overlay due to plants other than the targeted couple, a white sheet was positioned behind the target plant couple itself (Figure 3).

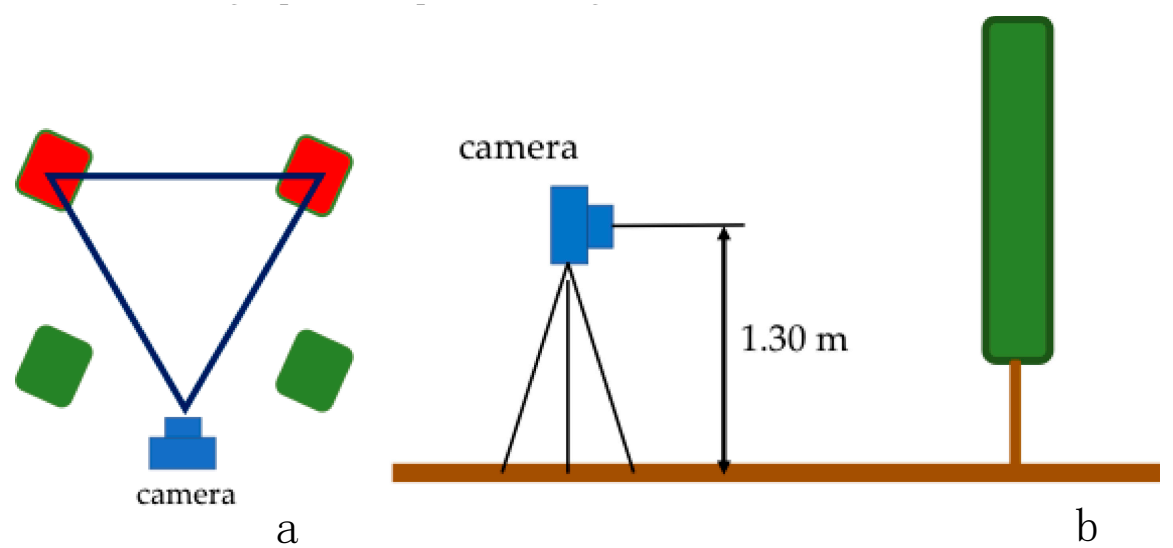

Figure 2. (a) Camera position in relation to the considered pair of plants. (b) Camera position in relation to the ground. 


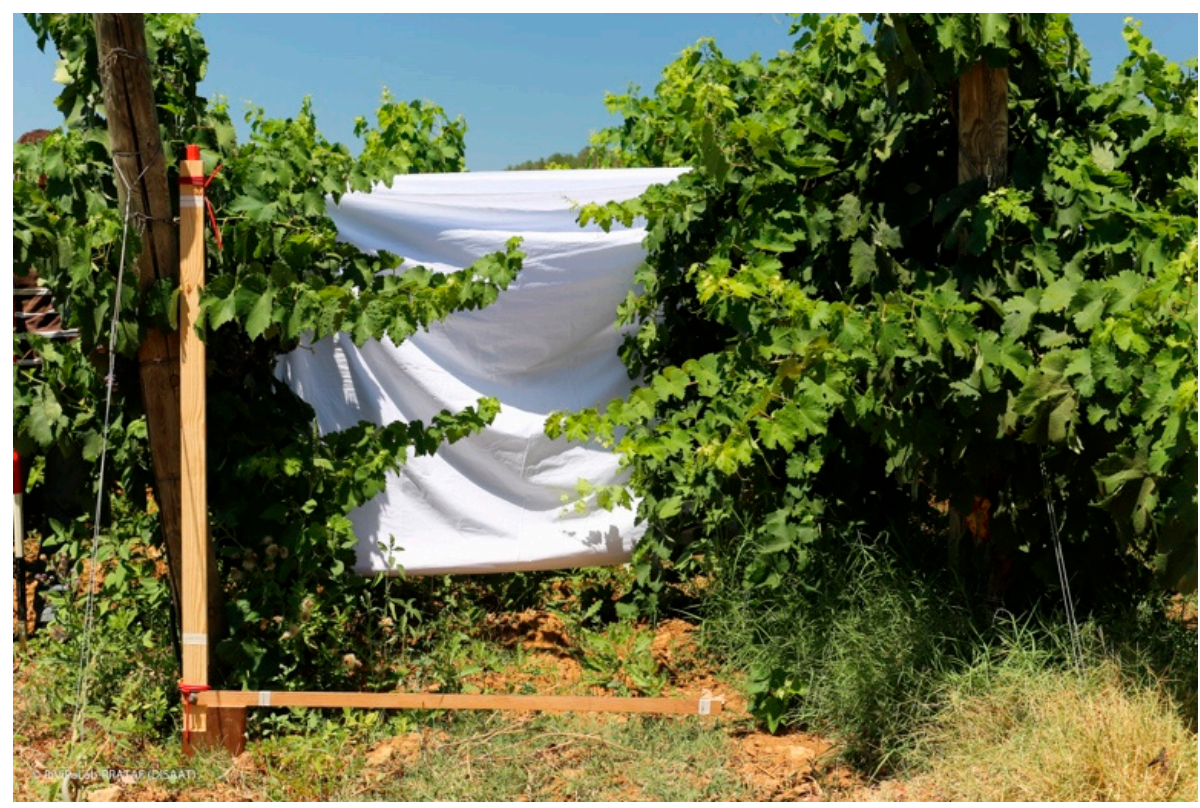

Figure 3. The wooden square angle ruler and sheet arranged on a pair of plants.

To obtain pictures that could be corrected for possible geometrical aberration, a square angle ruler was used, consisting of two 2-metre wooden bars, joined at their ends to form a right angle disposed with the horizontal axis overlapped to the axis that joined each of the plants of the couple that was photographed. A spirit level was used in order to guarantee the exact horizontality of the ruler's horizontal axis and of the verticality of the vertical axis with reference to the ground plane. Each picture was georeferenced (Figure 3).

Each of the ten different pictures obtained for each different vineyard cultivar was in-office elaborated using Autodesk Autocad 3D 2018 software by means of the following procedure:

(a) a 2.00 meter sided square was drawn on a specific Autocad layer with the lower-left corner located in the origin of Autocad's $x O y$ Cartesian reference system;

(b) the raster image was imported in Autocad, taking care that the crossing point of the photographed wood axis matched with one of the previously designed square's corner;

(c) the raster image was stretched in order to ensure that the 2-metre distant reference points on the photographed wooden axis matched with two pertinent corners of the previously designed square. The reason for this procedure was to both resize the picture in the right way and to correct possible geometrical aberration;

(d) using the polyline Autocad command, a specific polyline was drawn on an Autocad specific layer in order to contour the vineyard canopy;

(e) using the list Autocad command, the polyline vertex coordinates were exported for further use.

All of the Autocad-acquired vertex coordinates were used to obtain, by means of Microsoft Excel 365 software, a 5th grade tendency curve that was used to represent (corrected and smoothed through "spline" command) in Autocad the "characteristic contour" of the vineyard canopy. The described process was carried out for each considered cultivar in both Cantine Due Palme and Porrelli vineyards.

\section{Results and Discussion}

\subsection{The TRACLAS Project}

The TRACLAS project, which involved five Italian Universities Operational Units, started with detailed investigations on plant layout and cultivation methods of the main open field specialized 
crops carried out in Italy. Twenty farms situated in Lombardy, Emilia Romagna, Latium, Sicily and Apulia were then considered according to the greater extents of cultivation compared to the reference areas. The analyzed specialized crops were: vineyards for wine and table grapes, kiwi, hazelnuts, almonds, pistachio, olive oil and vegetables in open field and in tunnels, such as baby leaf salads, potatoes, cucumbers, ginger, etc. These crops were chosen on the basis of their problems connected to the operations carried out with tractors under the canopy; furthermore, the farms that were picked out were located in the areas with the highest impact production at a regional level for the aforesaid crops. At the beginning, the research evaluated the mechanization by the examined farms and then in each of them the main characteristics of the tractors and implements used for the agricultural operations carried out during the entire production cycle were detected. A total of 34 tractors and 46 implements were studied with reference to the sizes and construction characteristics, power and features of the coupled tractors, the operating speeds, and the theoretical and effective working capacity. Furthermore, in each sample farm, the operators were interviewed on the critical issues of their activities, with reference to the stability of the used tractors and their sizes compared to those of the vegetation. The operators were also consulted for their suggestions on technical characteristics and performance of a new compact tractor for specialized crops in order to obtain an optimal employment. In the subsequent phase of the research the transit areas under the canopy in the orchards of the examined farms were examined.

\subsection{Evaluation of the Overall Dimension of the Canopy of the Apulian Vineyards}

Processing of the splines representing the canopy contours observed in the various photographs made it possible to evaluate the maximum dimensions (overall width) of the best tractor to perform the tillage and treatments required during crop development. For example, Figure 4 shows the results obtained from the Cantine Due Palme guyot vineyard (cv. Negroamaro), and Figure 5 shows those from the Porrelli tendone vineyard. In particular, Figure 4 shows the set of 10 splines (green lines), respectively for the right-hand and left-hand sides, obtained using the corresponding photographs. Moreover, the spline shown (blue line) for each side represents the average vegetation contour. This blue line was the basis for hypothesizing the maximum compatible measurements of a tractor able to pass between the vine rows without interfering with the vegetation and fruit formation areas. In this type of vineyard, the width of the inter-row spacing for tractor transit is extremely important. Obviously, the height of the tractor is unimportant. However, Figure 5, shows the set of 10 splines (green lines), obtained using the corresponding images of the tendone vineyard. Here again, the blue line represents the average vegetation contour. In this type of vineyard, the height of the vegetative mass above the surface of the ground is extremely important, because it determines the total tractor height, which must allow the vehicle to operate effectively and at the same time ensure the safety of its driver.

Given the above considerations, the splines and relative characteristic contours were analysed for all the vineyards used, and the average height and minimum width of the inter-row spacing was determined for each one (Figure 6). Therefore, it was established that clearance below the canopy for the various cultivars grown in the two vineyards ranges in width between $1100 \mathrm{~mm}$ and $1400 \mathrm{~mm}$, and between 1600 and $1700 \mathrm{~mm}$ in height (Figure 6). 


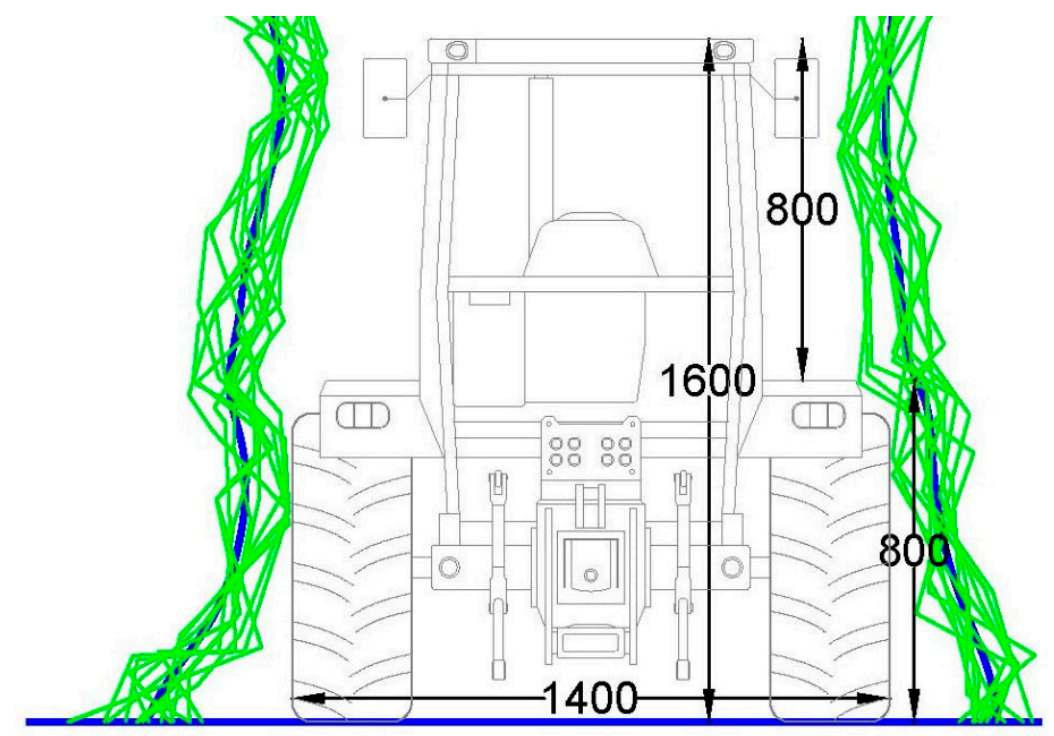

Figure 4. Guyot vineyard (located in Cellino San Marco, Brindisi Province, Southern Italy). Set of splines (green lines), characteristic contour of the vineyard canopy (blue line) and hypothetical size of the compact tractor (sizes in $\mathrm{mm}$ ).

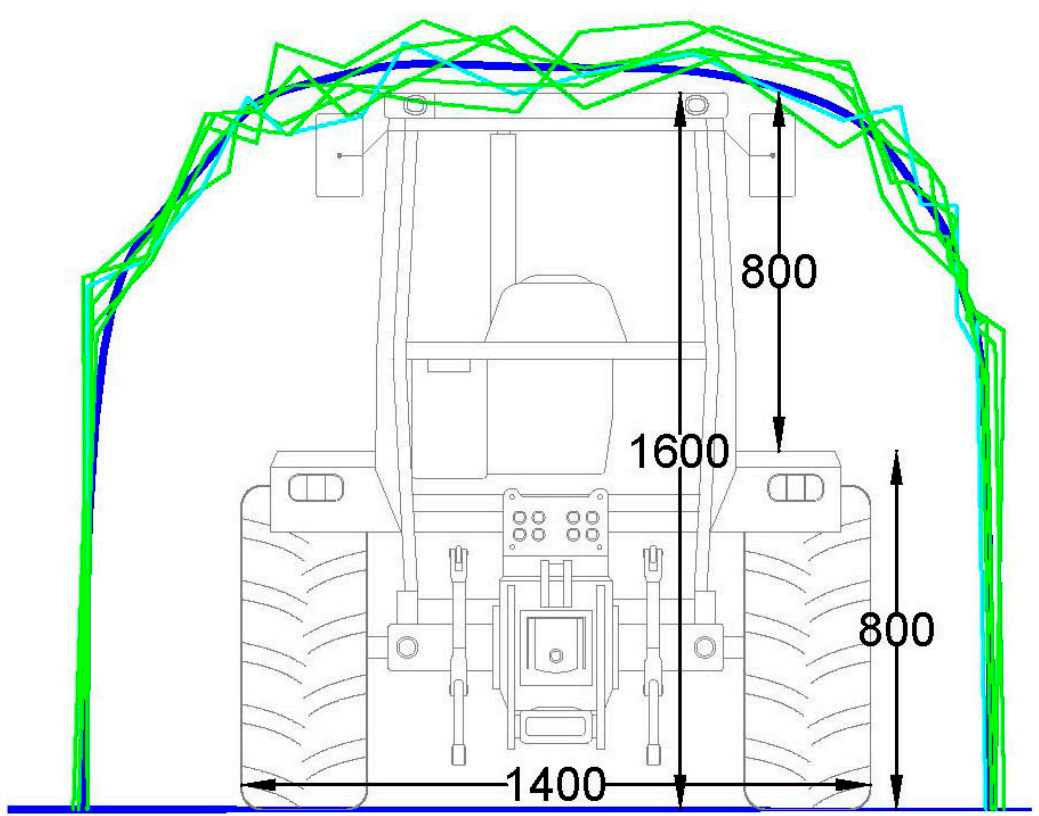

Figure 5. Tendone vineyard (located in Rutigliano, Bari Province, Southern Italy). Set of splines (green lines), characteristic contour (blue line) of the vineyard canopy and hypothetical size of the compact tractor (sizes in $\mathrm{mm}$ ). 


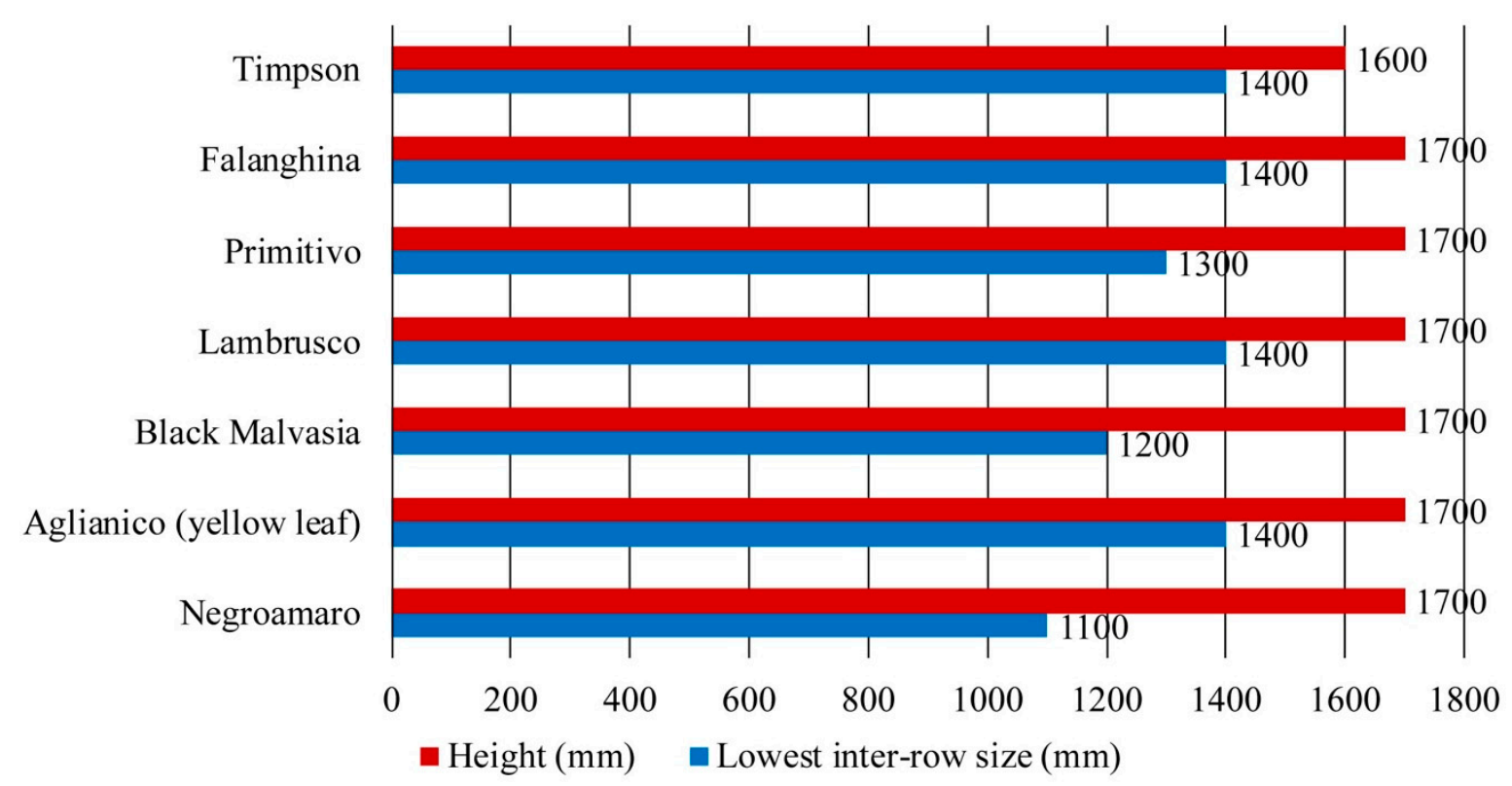

Figure 6. Average height and minimum width of the inter-row for each considered cultivar.

\subsection{The Evaluation of the Overall Size of the Compact Tractor Prototype}

The elaboration of: (i) the results obtained by the Operational Units concerning the characteristics of mechanization inside the examined farms; (ii) the considerations of the interviewed tractor drivers concerning the critical aspects of their activities and their proposals on the basic technical characteristics of an optimized tractor for their operations; (iii) the assessments of the overall dimension of the canopy inside the analyzed orchards, made it possible to establish the essential features of the compact tractor required by the TRACLAS project.

Therefore, the tractor prototype should be equipped with a 4-pillar frame ROPS and have the following main characteristics: (i) a max. height of $1600 \mathrm{~mm}$; (ii) a minimum front axle track of less than $1100 \mathrm{~mm}$ and a back axle track of less than $1000 \mathrm{~mm}$; (iii) a wheelbase of less than $2500 \mathrm{~mm}$. In addition, the overall length of the prototype should be under $4000 \mathrm{~mm}$, its maximum width less than $1400 \mathrm{~mm}$ and ground clearance greater than $200 \mathrm{~mm}$. The approach angle (both front and back, i.e., the angle made by the horizontal line of the ground surface and the tangent passing between the front wheel and the lowest protruding point of the vehicle) should be equal to or greater than $30^{\circ}$. The tractor prototype should supply a target power of about $74 \mathrm{~kW}$, be able to reach $40 \mathrm{~km} / \mathrm{h}$ and include the following main components: (i) integral braking on all 4 wheels; (ii) agricultural tires with a size not less than 240/70 R16; (iii) mechanical transmission with at least 4 gears and 3 ranges plus the reverser; (iv) 6-groove $35 \mathrm{~mm}$ diameter end shank with both $540 \mathrm{rpm}$ and $1000 \mathrm{rpm}$ operating mode; (v) hydraulic system with pump dedicated to distributors and lifter and additional pump dedicated to power steering; (vi) rear lift with a three-points hitch cat. II. Lastly, the prototype must ensure the tightest possible turning circle, which must not in any case exceed $6.00 \mathrm{~m}$.

Bearing in mind all these data, the Cordini manufacturer of Corato (Bari Province, Italy) built the compact tractor, starting from the Goldoni E100 commercial tractor (Figure 7). 


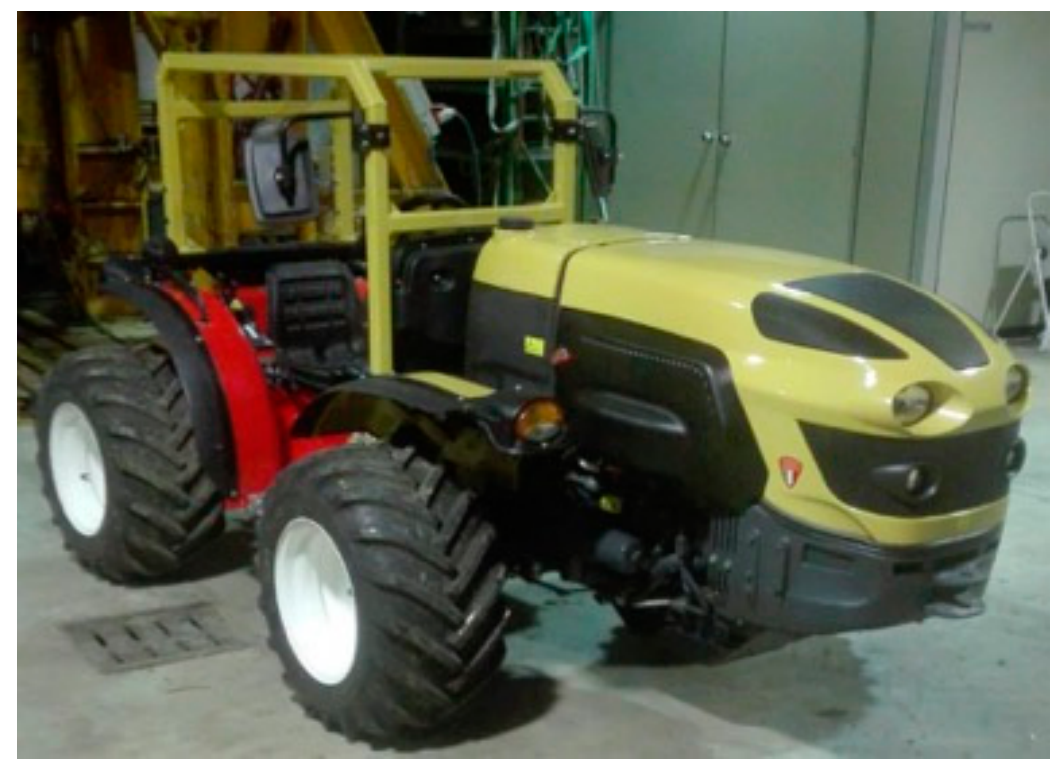

Figure 7. The built TRACLAS compact tractor.

\section{Conclusions}

The canopy size evaluations of the vineyards inside farms representing the most grape growing in Apulia (Southern Italy), were carried out within a project funded by the Italian National Insurance Institute for Occupational Labour (INAIL). This project was aimed at the definition and manufacture of a compact tractor prototype suitable for the use in specialized crops, which had to be equipped with a fixed ROPS and with limited dimensions (max height $1.60 \mathrm{~m}$ ), but comparable in terms of performance to the traditional tractor models of the same power class (about $74 \mathrm{~kW}$ ). The tractor was built and, in addition to its compactness, is characterized by a high transverse and longitudinal static stability, combined with excellent maneuverability and handiness. Further added value comes from the presence of a fixed 4-pillar ROPS, which is able to give constant and effective safeguard to the driver in the event of overturning. In agreement with the OECD Code 4 technical standard, the ROPS was tested successfully: it is able to safeguard the clearance zone, located with reference to the tractor driving place (operator's seat and steering-wheel). The compact tractor has also successfully undergone stability tests. Currently the operational units involved in the project are conducting experimental trials in the selected farms with the aim of comparing the operational effectiveness of the prototype tractor with that of other narrow- track tractors commonly used in the same farms.

Author Contributions: Conceptualization, S.P.; Methodology, S.P., A.S.A. and F.S.; Formal analysis, A.S.A. and F.S.; Investigation, S.P., A.S.A. and F.S.; Data curation, A.S.A. and F.S.; Writing-Original draft preparation, S.P.; Writing-Review and editing, S.P. and F.S.; Supervision, S.P. Many thanks to Sarah Jane Christopher for her translation and revision of the MS. All authors have read and agreed to the published version of the manuscript.

Funding: This research was funded by INAIL (the Italian National Insurance Institute for Occupational Labour) through the project "Messa a punto di un trattore agricolo a profilo compatto per le lavorazioni nelle coltivazioni arboree specializzate" and FONDAZIONE PUGLIA (Bari, Italy), which also supported this project.

Conflicts of Interest: The authors declare no conflict of interest.

\section{References}

1. Italian National Insurance Institute for Occupational Labour, INAIL, Historical Statistics. Available online: https://appsricercascientifica.inail.it/getinf_u/getinf.asp?a=2015\&i=2\&t=3\&s=\&w=a\&n= (accessed on 22 November 2019). 
2. Pascuzzi, S.; Santoro, F. Evaluation of farmers' OSH hazard in operation nearby mobile telephone radio base stations. In Proceedings of the 16th International Scientific Conference "Engineering for Rural Development" Proceedings, Jelgava, Latvia, 24-26 May 2017; Volume 16, pp. 748-5976.

3. Baldoin, C.; Balsari, P.; Cerruto, E.; Pascuzzi, S.; Raffaelli, M. Improvement in Pesticide Application on Greenhouse Crops: Results of a Survey about Greenhouse Structures in Italy. Acta Hortic. 2008, 801, 609-614. [CrossRef]

4. Myers, M.L. Tractor risk abatement and control as a coherent strategy. J. Agric. Saf. Health 2002, 8, 185-198. [CrossRef]

5. Bulgakov, V.; Pascuzzi, S.; Beloev, H.; Ivanovs, S. Theoretical investigations of the headland turning agility of a trailed asymmetric implement-and-tractor aggregate. Agriculture (Switzerland) 2019, 9, 224. [CrossRef]

6. Rondelli, V.; Casazza, C.; Martelli, R. Tractor rollover fatalities, analyzing accident scenario. J. Saf. Res. 2018, 67, 99-106. [CrossRef] [PubMed]

7. Cecchini, M.; Monarca, D.; Colantoni, A.; Di Giacinto, S.; Menghini, G.; Longo, L. Study on the possibility of application of a compact roll over protective structure for agricultural wheeled narrow track tractors. J. Agric. Eng. 2013, 44.

8. Mashadi, B.; Nasrolahi, H. Automatic control of a modified tractor to work on steep side slopes. J. Terramechanics 2009, 46, 299-311. [CrossRef]

9. Bulgakov, V.; Pascuzzi, S.; Adamchuk, V.; Ivanovs, S.; Pylypaka, S. A theoretical study of the limit path of the movement of a layer of soil along the plough mouldboard. Soil Tillage Res. 2019, 195, 104406. [CrossRef]

10. Kim, H.J.; Choi, S.; Kim, K.W.; Kim, J.S.; Kim, J.O.; Kim, Y.Y.; Kim, H.K.; Kwon, S.H. A study on improving the tractor ROPS and seat belt use of Korean farmers. In Proceedings of the American Society of Agricultural and Biological Engineers Annual International Meeting, Louisville, Kentucky, 7-10 August 2011.

11. Myers, J.R. Prevalence of roll-over protective structure (ROPS)-equipped tractors on hispanic-operated farms in the United States. J. Agromedicine 2010, 15, 137-147. [CrossRef]

12. Mattetti, M.; Molari, G.; Sereni, E. Damage evaluation of driving events for agricultural tractors. Comput. Electron. Agric. 2017, 135, 328-337. [CrossRef]

13. Hoy, R.M. Farm tractor rollover protection: Why simply getting rollover protective structures installed on all tractors is not sufficient. J. Agric. Saf. Health 2009, 15, 3-4.

14. Cerruto, E.; Manetto, G.; Santoro, F.; Pascuzzi, S. Operator dermal exposure to pesticides in tomato and strawberry greenhouses from hand-held sprayers. Sustainability (Switzerland) 2018, 10, 2273. [CrossRef]

15. Kelsey, T.W.; May, J.J.; Jenkins, P.L. Farm tractors, and the use of seat belts and roll-over protective structures. Am. J. Ind. Med. 1996, 30, 447-451. [CrossRef]

16. Molari, G.; Rondelli, V. Evaluation criteria for the anchorage resistance of safety belts on agricultural tractors. Biosyst. Eng. 2007, 97, 163-169. [CrossRef]

17. Mangado, J.; Arana, J.I.; Jarén, C.; Arazuri, S.; Arnal, P. Design calculations on roll-over protective structures for agricultural tractors. Biosyst. Eng. 2007, 96, 181-191. [CrossRef]

18. Khorsandi, F.; Ayers, P.D.; Jackson, D.L.; Wilkerson, J. The effect of speed on foldable ROPS actuation forces. J. Agric. Saf. Health 2016, 22, 285-298.

19. Bulgakov, V.; Pascuzzi, S.; Nadykto, V.; Ivanovs, S. A mathematical model of the plane-parallel movement of an asymmetric machine-and-tractor aggregate. Agriculture (Switzerland) 2018, 8, 151. [CrossRef]

20. Bulgakov, V.; Pascuzzi, S.; Santoro, F.; Anifantis, A.S. Mathematical Model of the Plane-Parallel Movement of the Self-Propelled Root-Harvesting Machine. Sustainability (Switzerland) 2018, 10, 3641. [CrossRef]

21. Nichol, C.I.; Sommer, H.J.; Murphy, D.J. Simplified overturn stability monitoring of agricultural tractors. J. Agric. Saf. Health 2005, 11, 99-108. [CrossRef]

22. Myers, J.; Cole, H.; Westneat, S. Seatbelt use during tractor overturns. J. Agric. Saf. Health 2006, 12, 46. [CrossRef]

23. Bambach, M.R.; Grzebieta, R.H.; McIntosh, A.S. Thoracic injuries to contained and restrained occupants in single-vehicle pure rollover crashes. Accid. Anal. Prev. 2013, 50, 115-121. [CrossRef]

24. Anifantis, A.S.; Camposeo, S.; Vivaldi, G.A.; Santoro, F.; Pascuzzi, S. Comparison of UAV photogrammetry and 3D modeling techniques with other currently used methods for estimation of the tree row volume of a super-high-density olive orchard. Agriculture (Switzerland) 2019, 9, 233. [CrossRef]

25. Bulgakov, V.; Pascuzzi, S.; Anifantis, A.S.; Santoro, F. Oscillations Analysis of Front-Mounted Beet Topper Machine for Biomass Harvesting. Energies 2019, 12, 2774. [CrossRef] 
26. Regazzi, N.; Maraldi, M.; Molari, G. A theoretical study of the parameters affecting the power delivery efficiency of an agricultural tractor. Biosyst. Eng. 2019, 186, 214-227. [CrossRef]

27. Pascuzzi, S. A multibody approach applied to the study of driver injuries due to a narrow-track wheeled tractor rollover. J. Agric. Eng. 2015, 46, 105-114. [CrossRef]

28. Pascuzzi, S.; Santoro, F. Analysis of the almond harvesting and hulling mechanization process: A case study. Agriculture (Switzerland) 2017, 7, 100. [CrossRef]

29. Pascuzzi, S. Outcomes on the Spray Profiles Produced by the Feasible Adjustments of Commonly Used Sprayers in "Tendone" Vineyards of Apulia (Southern Italy). Sustainability (Switzerland) 2016, 8, 1307. [CrossRef]

30. Molari, G.; Rondelli, V. On the Definition of Narrow-track Wheeled Agricultural Tractors. Biosyst. Eng. 2004, 88, 75-80. [CrossRef]

31. Fabbri, A.; Molari, G. Static Measurement of the Centre of Gravity Height on Narrow-track Agricultural Tractors. Biosyst. Eng. 2004, 87, 299-304. [CrossRef]

32. Melvin, L.M.; Henry, P.C.; Susan, C.W. Injury severity related to overturn characteristics of tractors. J. Saf. Res. 2009, 40, 165-170.

33. Santoro, F.; Anifantis, A.S.; Ruggiero, G.; Zavadsky, V.; Pascuzzi, S. Lightning Protection Systems Suitable for Stables: A Case Study. Agriculture (Switzerland) 2019, 9, 72. [CrossRef]

34. Anifantis, A.S.; Pascuzzi, S.; Scarascia Mugnozza, G. Geothermal source heat pump performance for a greenhouse heating system. An experimental study. J. Agric. Eng. 2016, 47, 164-170. [CrossRef]

35. Pascuzzi, S.; Santoro, F.; Manetto, G.; Cerruto, E. Study of the correlation between foliar and patternator deposits in a "Tendone" vineyard. Agric. Eng. Int. CIGR J. 2018, 20, 97-107.

(C) 2020 by the authors. Licensee MDPI, Basel, Switzerland. This article is an open access article distributed under the terms and conditions of the Creative Commons Attribution (CC BY) license (http://creativecommons.org/licenses/by/4.0/). 